\title{
Heart rate and swimming activity as indicators of post-surgical recovery time of Atlantic salmon (Salmo salar)
}

\author{
M. Føre ${ }^{1,2^{*}} \mathbb{D}$, E. Svendsen ${ }^{1,2}$, F. Økland ${ }^{3}$, A. Gräns ${ }^{4}$, J. A. Alfredsen², B. Finstad ${ }^{3,5}$, R. D. Hedger ${ }^{3}$ and I. Uglem ${ }^{3}$
}

\begin{abstract}
Background: Fish telemetry using electronic transmitter or data storage tags has become a common method for studying free-swimming fish both in the wild and in aquaculture. However, fish used in telemetry studies must be handled, anaesthetised and often subjected to surgical procedures to be equipped with tags, processes that will shift the fish from their normal physiological and behavioural states. In many projects, information is needed on when the fish has recovered after handling and tagging so that only the data recorded after the fish has fully recovered are used in analyses. We aimed to establish recovery times of adult Atlantic salmon (Salmo salar) after an intraperitoneal tagging procedure featuring handling, anaesthesia and surgery.

Results: Based on ECG and accelerometer data collected with telemetry from nine individual Atlantic salmon during the first period after tagging, we found that heart rate was initially elevated in all fish and that it took an average of $\approx 4$ days and a maximum of 6 days for heart rate to return to an assumed baseline level. One activity tag showed no consistent decline in activity, and two others did not show strong evidence of complete recovery by the end of the experiment: baseline levels of the remaining tags were on average reached after $\approx 3.3$ days.
\end{abstract}

Conclusion: Our findings showed that the Atlantic salmon used in this study required an average of $\approx 4$ days, with a maximum interval of 6 days, of recovery after tagging before tag data could be considered valid. Moreover, the differences between recovery times for heart rate and activity imply that recovery time recommendations should be developed based on a combination of indicators and not just on e.g. behavioural observations.

Keywords: Fish telemetry/biologging, Atlantic salmon, Post-tagging recovery, Heart rate, Swimming activity

\section{Background}

Fish telemetry/biologging is a method of monitoring freeswimming fish where individual animals are equipped with electronic tags that often contain sensors for collecting data on the conditions within or near the fish $[1,2]$. Such tags may either be transmitter tags transferring data wirelessly to the user (see [3] for details on the structure of an electronic transmitter tag) or data storage/archival

*Correspondence: martin.fore@ntnu.no

${ }^{1}$ Department of Engineering Cybernetics, Norwegian University of Science and Technology, 7491 Trondheim, Norway

Full list of author information is available at the end of the article tags (DSTs) that store data in internal storage mediums accessible only after the fish (and tag) has been recaptured [2]. Irrespective of tag type, most studies using such methods aim to assess the status of wild fish in ecological settings (e.g. $[4,5])$, to evaluate how fish communities respond to man-made structures (e.g. [6]), or as a tool to provide knowledge for fisheries management (reviewed by [7]). The interest in using this approach in aquaculture is also increasing, both because ongoing technological advances are rapidly expanding the possibilities [8], and because new production philosophies such as Precision Fish Farming promote monitoring at an individual level [9]. Example uses of telemetry/biologging in aquaculture 
include studies to assess fish responses during welfarecritical operations such as crowding (e.g. [10]) and transport (e.g. [11]), and responses to environmental variability such as temperature variations (e.g. [12]).

In animal monitoring, it is essential to ensure that the observed animals are representative of the targeted population. When using telemetry, the fish selected for tagging must therefore be representative both before and after the tags are deployed. Ideally, this means that the selection of fish should be truly random and representative and that the tags do not influence physiology or behaviour in such a way that the tagged fish differ significantly from untagged fish (e.g. [13]). In addition, tagging procedures include several steps (e.g. handling, anaesthesia and surgical procedures) that may induce stress, that in turn may lead to physiological and/or behavioural changes in the fish [2,14-17]. Acute (short term) followed by chronic (long term) stress in farmed fish may lead to undesirable effects such as reduced disease resistance, reduced growth rates, impaired health, and increased mortality [18-21]. Stress responses in fish are described by primary responses that include the release of stress hormones such as catecholamines and cortisol into the circulation system, followed by secondary responses such as changes in glucose levels, electrolyte balance and heart rate and, finally tertiary (whole animal) responses. If the fish is unable to acclimate to the stressor at this stage, effects such as behavioural changes, decreased reproductive capacity and growth may occur, sometimes even resulting in that the animal dies (see [22] and references therein). If such changes are chronic, the fish cannot be considered representative of the population and should be excluded from further analyses $[1,23]$. Conversely, if the changes are transient, the fish may be considered fully recovered once the response patterns return to those expected from an untagged fish. This means that tagged fish can be used in analyses if the data from the period of recovery are excluded. However, this also raises the question: how can we define when a fish is properly recovered after a tagging procedure?

Jepsen et al. [16] sought to identify the duration of post-surgery recovery for Chinook salmon (Oncorhynchus tshawytscha) by studying changes in commonly used blood indicators of the primary (cortisol) and secondary (glucose and lactate) stress responses in teleosts. The authors found that all measured parameters decreased from initially elevated levels to within normal ranges within 7 days post-surgery, with glucose and lactate (substrate and by-product, respectively, of elevated anaerobic metabolism) normalising during the first $24 \mathrm{~h}$, a recovery time resembling that seen in several studies (e.g. [24, 25]). Coping with stress is also an energy-demanding process [26] and one of the most common indicators of metabolic effects due to stress is the increase in plasma glucose concentration [22]. Such changes have recently been shown to lead to increased heart rates also in fish [27]. Other studies have aimed to evaluate post-surgery recovery by comparing the behaviour of the tagged fish to their behaviour before surgery or in untagged cohabitant fish. This method has for instance been applied in laboratory experiments with tilapia (Tilapia sp.) who appeared fully recovered $24 \mathrm{~h}$ post-surgery after displaying loss of equilibrium and reduced swimming activity and feeding just after tagging [17]. Swimming activity was then assessed by measuring the posture of the fish, and presented as the percentage of the time the fish was resting (assuming an oblique angle with the snout towards the surface) or actively swimming (horizontal orientation or snout pointing toward the bottom).

Recovery after tagging may also be studied with sensor telemetry. The information conveyed by the tag must then reflect the state of the fish, and typical sensor values for unstressed fish should be available as a baseline for comparison. Previous studies using this approach include using heart rate tags to compare tagging methods for black cod (Paranotothenia angustata, [14]), and more recently to study post-surgery stress-responses [28] and potential effects of antibiotics on post-surgical recovery [29] in rainbow trout (O. mykiss). While Brijs et al. [28] implied a recovery from surgical implantation $>72 \mathrm{~h}$, Hjelmstedt et al. [29] demonstrated a decrease in heart rate to within baseline levels $72-96 \mathrm{~h}$ after anaesthesia and surgery. Other sensor measurements that could potentially be used in this way include tri-axial accelerometers, as previous studies have identified links between accelerometer-based activity proxies that are particularly sensitive to tail beat frequency and amplitude and orientation changes, and stress in salmon [10,30].

Although Atlantic salmon (Salmo salar) has been frequently studied using telemetry, there is still a lack of detailed quantitative information on the post-surgery recovery of this species. We, therefore, sought to identify the recovery time of Atlantic salmon after intraperitoneal tagging. This was done using heart rate and acceleration data collected using intraperitoneally implanted electronic tags, meaning that data could be collected without introducing the additional handling stress that would accompany other methods such as blood sampling. The parameters were chosen because they have previously been found to be linked with stress (e.g. $[10,28,31])$ and welfare [32] in salmonids and are commercially available in archival and telemetry tags. The data were collected in a controlled experiment in tanks studying how stress responses in Atlantic salmon can be measured using state-of-the-art technology. The stress response part of 
this experiment is described in greater detail by Svendsen et al. [27].

\section{Materials and methods}

\section{Experimental site and fish}

The experiments were conducted at the NINA Ims Research Station near Stavanger, Norway, between January and March 2019, using 60 hatchery-reared adult Atlantic salmon of the Aqua Gen strain (mean $55.5 \pm$ stdev $5.7 \mathrm{~cm}$ fork length, mean weight $2100 \mathrm{~g}$ ). The experiment started on January 28th by stocking four square tanks (tank 1-4, $215 \mathrm{~cm}$ side, $122 \mathrm{~cm}$ depth, $5600 \mathrm{~L}$ ) with seven fish each. The fish were then allowed to habituate to the tanks for a period of 21 days until February 18th when three fish in each of tanks 1-4 were selected at random and equipped with tags, resulting in 12 tagged fish in total (Table 1 ).

The tanks were set up with flow-through configuration, with filtered fresh water from the nearby Imsa river mixed with small amounts (3-6 ppt, average $5 \mathrm{ppt}$ ) of seawater supplied from seawater inlets at $30 \mathrm{~m}$ depth to ensure a stable and homogeneous water quality and avoid the introduction of parasites and pathogens to the tanks. Consequently, tank water properties followed the ambient conditions in the river, temperatures increasing from 3.9 to $5.0^{\circ} \mathrm{C}$ and with DO varying between 93.8 and $101.2 \%$ between the start and end of the experiment (March 15th). Oxygen sensors and oxygenation were also used to prevent unfavourable DO levels. The fish were fed once per day between 08:00 and 10:00 in the morning throughout the entire experimental period, with each meal consisting of $2 \mathrm{dL} \mathrm{tank}^{-1}$ (Skretting Røye Vitalis
600-60A $7 \mathrm{~mm}$ pellets). The fish were not subjected to any fasting during the experiment period.

\section{Biotelemetry/logging systems and surgical procedures}

All 12 tagged fish (Table 1) were equipped with one of three different types of heart rate monitoring Data Storage Tags (DSTs, Star Oddi Ltd.): $4 \times$ DST milliHRT $(39.5 \times 13 \mathrm{~mm}, 11.8 \mathrm{~g}$ in air); $4 \times$ DST centiHRT $(46 \times 15 \mathrm{~mm}, 19 \mathrm{~g}) ; 4 \times$ DST centi-HRT ACT $(46 \times 15 \mathrm{~mm}, 19 \mathrm{~g})$. Using different DST types rather than equipping all fish with the same tag types allowed us to also investigate whether all three tag varieties would be suitable for experiments with Atlantic salmon, which is relevant because this is one of the first applications of this technology on this species. Furthermore, since all three tag types were from the same provider, contained the same type of heart rate sensor and comparable sampling frequencies $(80 \mathrm{~Hz}$ over $7.5 \mathrm{~s}$ per $\mathrm{HR}$ sample point for the centi tags and $100 \mathrm{~Hz}$ over $15 \mathrm{~s}$ per HR sample point for the milli tags), and applied the same post-processing methods to the resulting data, they provided heart rate data sets that were comparable among tags. The milliHRT type was set with a higher sample storage interval (10 $\mathrm{min})$ than the others $(5 \mathrm{~min})$ as they used more of their internal storage medium for raw ECG traces. All data were timestamped using the tag internal clocks to facilitate comparison, and eventual clock drift between individual clocks was negligible compared to the time scale of the experiment. One tag type (DST centi-HRT ACT) also measured activity using an embedded tri-axial accelerometer (1 Hz sampling rate).

In addition to the DSTs that were applied, a total of 4 tagged fish (two fish each from tanks 1 and 2, Table 1)

Table 1 Information about the tagged individuals used in the study

\begin{tabular}{|c|c|c|c|c|c|c|c|c|c|}
\hline Fish \# & $\begin{array}{l}\text { Body length } \\
(\mathrm{cm})\end{array}$ & $\begin{array}{l}\text { Est. body } \\
\text { weight (kg) }\end{array}$ & Tank & DST type & Acoustic tag & $\begin{array}{l}\text { Time } \\
\text { anaesthesia } \\
\text { (mm:ss) }\end{array}$ & $\begin{array}{l}\text { Time surgery } \\
\text { (mm:ss) }\end{array}$ & Sex & Mature \\
\hline $\mathrm{F} 1$ & 59.5 & 2.3 & 1 & centi HRT & $x$ & 08:00 & 08:03 & $\mathrm{F}$ & \\
\hline $\mathrm{F} 2$ & 52 & 1.6 & 1 & centi HRT & $x$ & $08: 20$ & $08: 12$ & $\mathrm{~F}$ & \\
\hline F3 & 57 & 2.1 & 1 & milli HRT & & $08: 45$ & 06:31 & $\mathrm{F}$ & \\
\hline $\mathrm{F} 4$ & 63 & 2.8 & 2 & centi HRT ACT & $x$ & 08:06 & $06: 30$ & $M$ & $x$ \\
\hline F5 & 53 & 1.7 & 2 & centi HRT ACT & $x$ & $08: 30$ & $06: 50$ & F & $x$ \\
\hline F6 & 53 & 1.7 & 2 & milli HRT & & $07: 30$ & 06:00 & $M$ & \\
\hline F7 & 74 & 4.5 & 4 & centi HRT ACT & & $07: 40$ & 07:00 & $\mathrm{F}$ & \\
\hline F8 & 67 & 3.3 & 4 & centi HRT ACT & & 08:00 & $06: 30$ & $M$ & $x$ \\
\hline F9 & 55 & 1.9 & 4 & milli HRT & & 08:10 & 08:00 & $M$ & \\
\hline F10 & 62.5 & 2.7 & 3 & centi HRT & & 05:30 & 07:00 & $M$ & $x$ \\
\hline F11 & 61.5 & 2.6 & 3 & centi HRT & & 07:00 & $06: 30$ & $\mathrm{~F}$ & \\
\hline $\mathrm{F} 12$ & 55 & 1.9 & 3 & milli HRT & & 07:00 & $06: 50$ & $\mathrm{~F}$ & $x$ \\
\hline
\end{tabular}

Individual body weight was not measured and was hence estimated using an allometric model $\left(W=a L^{b}\right)$ with $a=0.0142$ and $b=2.9401$ 
were fitted with acoustic tags (A MP-9, $24.4 \times 9 \mathrm{~mm}$, $3.6 \mathrm{~g}$; Thelma Biotel AS) that contained tri-axial accelerometers (5 Hz sampling rate) and transmitted an activity proxy derived from the accelerometer measurements every $40 \mathrm{~s}$. These tags compute the proxy by first high pass filtering the accelerations from all three axes using a cutoff frequency of $0.2 \mathrm{~Hz}$ to remove low-frequency acceleration components due to gravity and body orientation. The remaining high-frequency components then mainly contain accelerations caused by features related to bodily movement that are of interest when evaluating activity levels, such as tail beats (frequency and amplitude) and rapid changes in attitude/orientation. The Euclidian norm of the three high pass filtered accelerometer axes is then computed to yield the magnitude of the total high pass filtered 3D acceleration sensed by the accelerometer. Although Føre et al. [10] used the same activity proxy with a maximum value of $3.465 \mathrm{~m} \mathrm{~s}^{-2}$, we chose to limit the proxy to $0-2.1 \mathrm{~m} \mathrm{~s}^{-2}$ in our study as this gave us a higher resolution and hence precision for the activity measures. Moreover, Føre et al. [10] observed very few activity values above $2 \mathrm{~m} \mathrm{~s}^{-2}$ in Atlantic salmon during stressing, implying that using a lower range would not compromise the ability to capture the dynamics associated with salmon swimming activity. To be comparable with the data from the acoustic tags, the activity data from the centi-HRT ACT DSTs were analysed similarly by applying filtering and computing the Euclidian norm as explained for the acoustic tags (see [27] for more details). Adding the acoustic tags thus allowed us to compare their activity proxies with those based on the acceleration data from the DSTs and resulted in that the experiment produced 12 data sets on heart rate, and 8 data sets on swimming activity. With mean fish weight being $2100 \mathrm{~g}$ and a maximum total tag weight carried by an individual at $22.6 \mathrm{~g}$ (DST centi-HRT + A MP-9) the tag vs. fish weight ratio of all fish were well within the informal rule of thumb of $2 \%$ for maximum tag mass relative to fish mass [2].

Each tag implantation was started by capturing a random fish from an experiment tank using a knotless dip net and immediately transferring it to an anaesthetic bath (Benzoak Vet, $70 \mathrm{mg} / \mathrm{L}$ ) where the fish was kept until it lost its equilibrium and stage III anaesthesia [33] was reached (average time $7.7 \mathrm{~min}$ ). The fish was then carefully placed with its ventral side up on a specialised surgical table with a v-shaped mid-section designed such that the head of the fish was immersed in water throughout the whole procedure. A hose circulating anaesthetic (Benzoak Vet, $35 \mathrm{mg} / \mathrm{L}$ ) through the orobranchial cavity of the fish was inserted into its mouth and the head was covered by a moist cloth (Fig. 1).

A $2-3 \mathrm{~cm}$ incision was made along the sagittal plane starting slightly more than one tag length (i.e. the length of the tag to be implanted) posterior from the transverse pericardial septum.

A finger was inserted through the incision to locate the transverse pericardial septum. While retaining the finger inside the peritoneal cavity for support, a needle was positioned in the skin just posterior to the transverse septum and slightly laterally from the sagittal plane. The finger was withdrawn, and a smooth plastic spoon inserted through the incision until it was just below the needle insertion point. The needle was then pushed

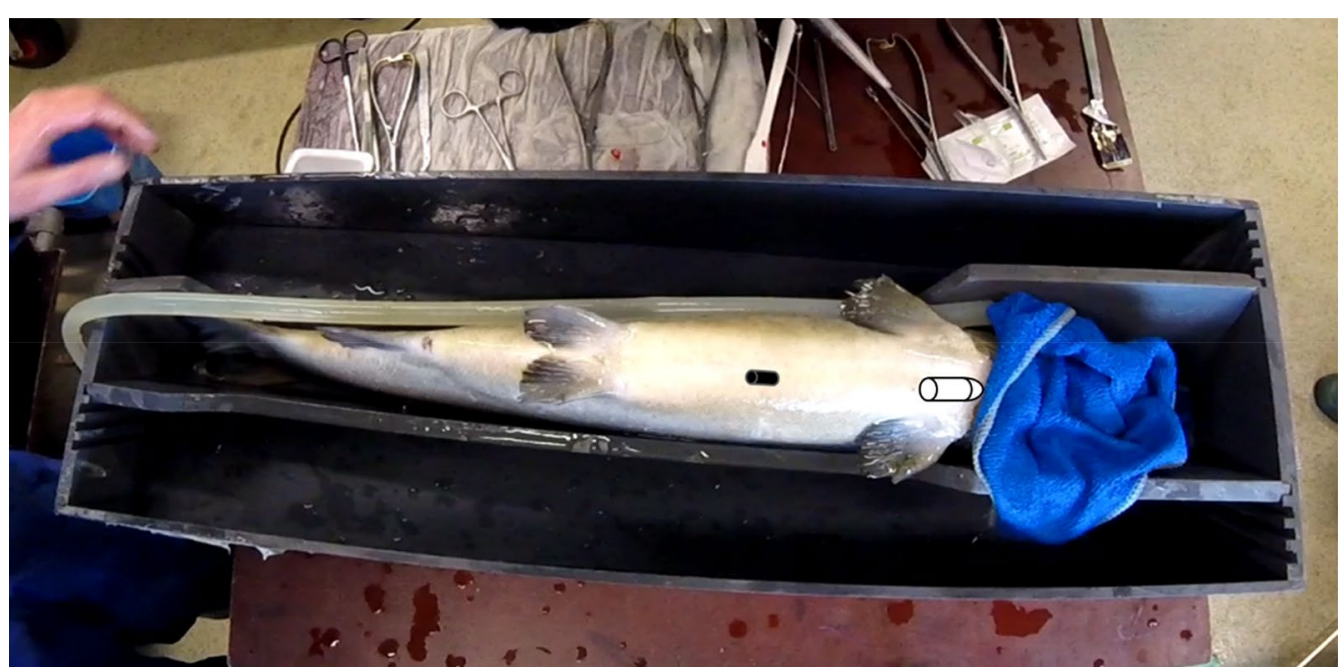

Fig. 1 Fish in the surgical table with anaesthetic circulation tube and head cover, indicating approximate locations of DSTs (white tag) and acoustic tags (black tag) after implantation 
through the peritoneal wall while simultaneously withdrawing the spoon to extract the needle out through the incision while protecting the viscera. One end of a suture threaded through the end of the tag was inserted into the tip of the needle. The needle was then withdrawn to pull the suture out through the needle's entry point. This procedure was then repeated on the other side of the sagittal plane. The tag was then inserted through the incision and anchored anteriorly in the peritoneal cavity using the suture and an (external) surgical knot. For the four fish also equipped with separate acoustic tags, the second tag was inserted into the peritoneal cavity through the same incision. Finally, the incision was closed using interrupted sutures. The fish was then transferred to a recovery tank with circulating seawater where it was kept until it regained consciousness, upon which it was transferred back into the tank it was collected from. See Table 1 for anaesthesia bath and surgery durations for all tagged fish.

\section{Timeline and experimental design}

Since the present study focused on investigating the posttagging recovery, the analyses only included data from the 2 weeks following tagging. To avoid inducing other stress effects that could disturb their recovery, the fish were sheltered from all potential stress factors except those necessary to feed and provide for the fish in this period.

None of the fish exhibited signs of adverse health after tagging or during the trials, and all fish were euthanised after the conclusion of the experiment. Posthumous pathology of all remaining experimental fish at the end of the experiment (19 female, 23 male) revealed that about one-third of these fish (14 in total, 8 F, $6 \mathrm{M}$ ) exhibited signs of sexual maturation through the experimental period, including 5 of the tagged individuals (Table 1 ). Although this appeared to have a little direct impact on the fish in three of the tanks, the data from the fish in one of the tanks (tank 3) were excluded from the statistical data analyses due to perpetual inter-individual aggression between two matured males in that tank throughout the experimental period. This left nine fish tagged with DSTs measuring heart rate, six of which also measured activity. Since two of these fish contained both a DST and an acoustic tag measuring activity, this resulted in a total of eight time-series of activity.

\section{Data processing and statistics}

Heart rate data were used as downloaded from the DSTs. Outliers were removed using the Median Absolute Deviation (MAD) approach [34], using a MAD decision criterion of 3 , which is a conservative value (see [35]). The MAD decision criterion denotes the standard deviation from the dataset's sample average above which samples are rejected. The MAD decision criterion typically ranges from 2 (poorly conservative) to 3 (very conservative). In this study, the choice of 3 is justified by the measured heart ranges compared to typical heart rates published in the literature $(15<\mathrm{HR}<80)$ for Atlantic salmon and comparable species [28, 36]. Activity data from the DST centi-HRT ACT tags were downloaded as raw acceleration values along all three axes and then subjected to similar post processing as that used to compute the activity proxy in the A MP-9 acoustic transmitter tags to yield a comparable measure of activity between the two tag types.

In a non-decomposed time-series, circadian variation (that between day and night) and irregular variation (that other than circadian of long-term) had the potential to obscure long-term trends in heart rate and activity. Time-series of heart rate and activity were therefore first decomposed into circadian, long-term trend, and irregular components. Decomposition, and subsequent removal of the circadian and irregular components of the time-series, leaving a long-term component (that showed the long-term growth or decline of the time-series values over the temporal extent of the series), allowed for the examination of the form of the long-term trends towards recovery. To decompose each time-series, it was first binned into 15 min intervals (each 15 min interval showing a mean heart rate or intensity over that interval) and then converted into a time-series object [ $\mathrm{R}$ function $t$ s \{stats\}; Becker et al. [37]]. Time-series objects were then decomposed using the Seasonal Decomposition of Time Series by Loess $\mathrm{R}$ function stl \{stats\} (B. D. Ripley; Fortran code by Cleveland et al. [38] from "netlib"). Long-term trend components were then analysed for a systematic change in heart rate or activity that could be indicative of a post-surgery recovery by first modelling the temporal relationship and then compartmentalising this into preand post-recovery phases.

The relationship between the long-term trend component of heart rate or activity $(y)$ and time post-tagging $(t)$ was modelled using an exponential decay model:

$$
y(t)=y_{\mathrm{p}}+\left(y_{0}-y_{\mathrm{p}}\right) e^{-\alpha t},
$$

where $\alpha$ defines the decay constant from $y_{0}$ (at time zero) to $y_{\mathrm{p}}$, the model plateau. Models were fitted with the nls \{stats\} R function (D. M. Bates and S. DebRoy: D. M. Gay for the Fortran code used by algorithm = "port"), using the self-starting asymptotic regression function SSasymp \{stats\} (J. Pinheiro and D. M. Bates). Most trend components followed an exponentially decaying pattern, ensuring model convergence, but some included parts that were inconsistent 
with an exponential decay. First, some tags (three heart-rate tags and four activity tags) showed a short initial post-surgery increase in registered values at the beginning of the experiment. Secondly, some tags (one heart rate and two activity tags) showed an increase in registered values after $\approx 5-6$ days. This late increase in activity or heart-rate was likely a result of a separate, post-recovery change in behaviour of these individuals. To ensure model convergence, these parts of the longterm trend components were removed prior to model fitting. That is, the exponential model was only fitted to parts of the long-term trend component that were consistent with a post-surgery exponential decline. One activity tag (fish F4 in tank 8) did not show an exponential decline with time and was thus not fitted with a model.

Identification of breakpoints between pre- and postrecovery phases was done on an individual basis. The breakpoint between pre- and post-recovery for each tag was set where the heart rate or activity reached a recovery threshold, defined as the heart rate or activity level delimiting those pre- and post-recovery. A recovery threshold was defined for each tag as the mean $+2 \mathrm{SD}$ of the long-term trend component values calculated from the final 3 days of the fitted series. Inspection of the tags showed that trend components were approaching asymptotes in the final 3 days, so it was reasonable to assume that values from these days represented postrecovery signature. Thresholds were established on an individual basis to allow for post-recovery heart rate or activity to change according to individuals.

\section{Results}

\section{Post-surgery recovery}

Daily heart rate significantly declined from a mean of $36.0 \mathrm{bpm}$ (range $=24.6-45.6, \mathrm{SD}=5.6, n=9$ ) on the day of surgery to a mean of $22.3 \mathrm{bpm}$ (range $=17.5-26.6$, $\mathrm{SD}=2.6, n=9) 13$ days later (one-sided Wilcoxon's rank test, $V=45, p=0.002$ ) (Fig. 2a; raw data for all tags shown in). Daily activity significantly declined from a mean of $0.57 \mathrm{~m} \mathrm{~s}^{-2}$ (range $=0.26-0.92, \mathrm{SD}=0.23, n=8$ ) on the day of surgery to a mean of $0.33 \mathrm{~m} \mathrm{~s}^{-2}$ (range $=0.27$ $0.41, \mathrm{SD}=0.06, n=8) 13$ days later (one-sided Wilcoxon's rank test, $V=45, p=0.008$ ) (Fig. 2b). However, individual variation in activity was high (Fig. 2b). Both heart rate and activity displayed circadian variation. Heart rate was greater during daytime (mean $=25.8 \mathrm{bpm}$, range $=22.2-26.7, \mathrm{SD}=1.9, n=9$ ) than during night $($ mean $=22.7 \mathrm{bpm}$, range $=19.6-24.9, \mathrm{SD}=1.9, n=9)$ (Fig. 2a; raw data for all tags shown in Additional file 1: Figures S1, S2). In contrast, activity was greater during night $\left(\right.$ mean $=0.47 \mathrm{~m} \mathrm{~s}^{-2}$, range $=0.32-0.60, \mathrm{SD}=0.11$,
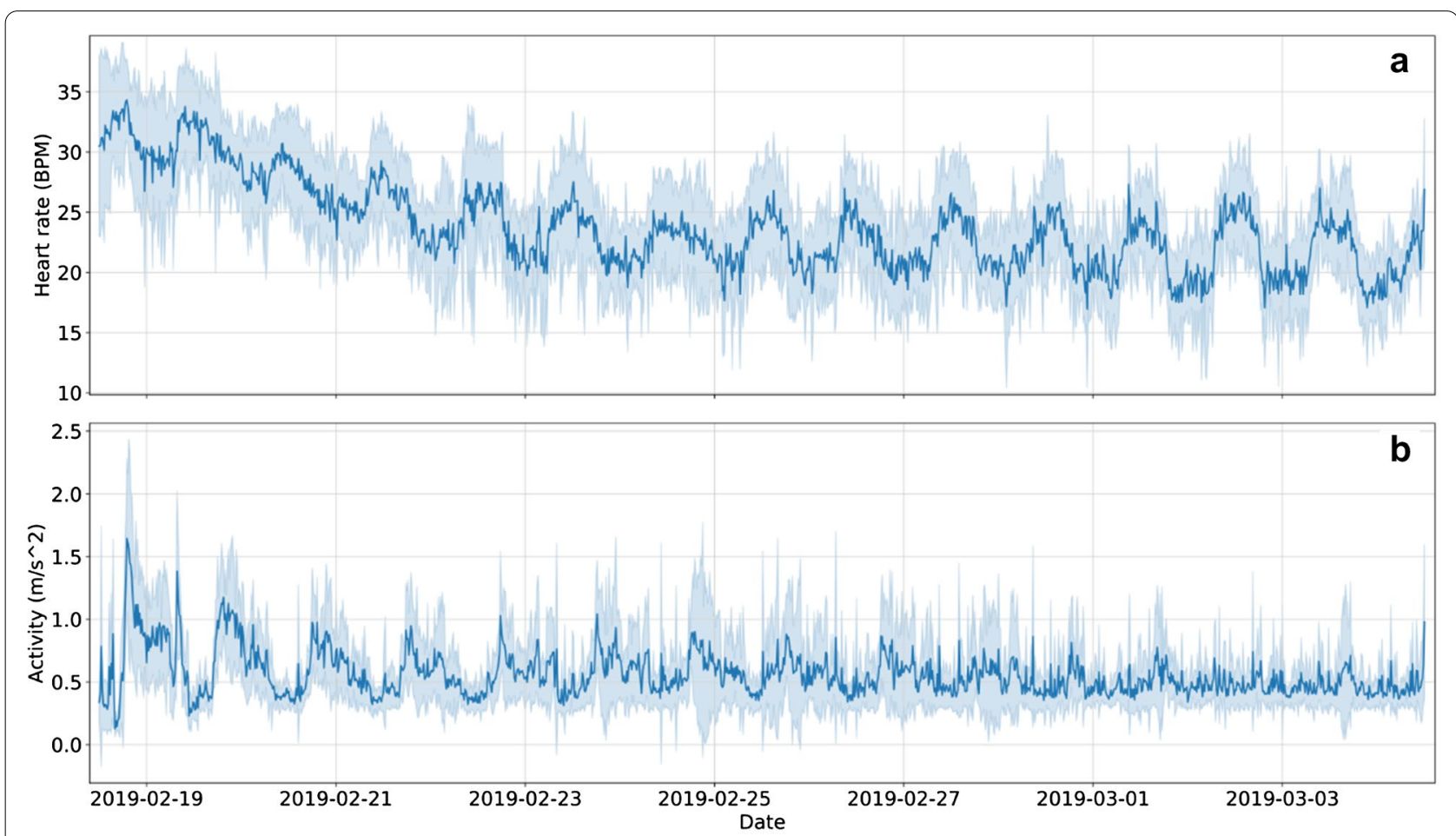

Fig. 2 Average a heart rate and $\mathbf{b}$ activity values (blue line) from all fish in tanks 1, 2 and 4 (tank 3 was excluded because of aggressive behaviour between two males) for the first 2 weeks post tagging. The light-blue envelope shows the range in heart rate values of all individuals 
$n=8)$ than during daytime $\left(\right.$ mean $=0.34 \mathrm{~m} \mathrm{~s}^{-2}$, range $=0.25-0.43, \mathrm{SD}=0.06, n=8$ ) (Fig. $2 \mathrm{~b}$; raw data for all tags shown in Additional file 1: Figures S3, S4). Circadian differences were present throughout the experiment. However, the circadian difference in activity declined throughout the experiment. This circadian variation was shown by all individuals, as revealed by the circadian components from the time series (Additional file 1: Figures S5, S6). There was generally greater activity during the evening than during morning (Additional file 1: Figure S6).

The heart rate trend component showed a decline that could be modelled with an exponential decay function (Fig. 3). However, the trend component still

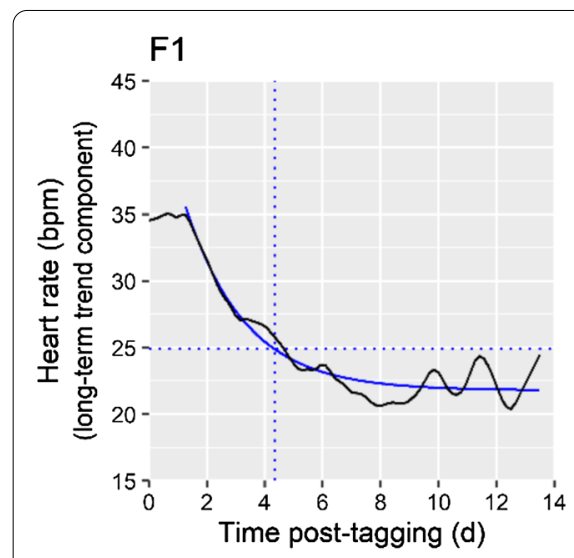

F4

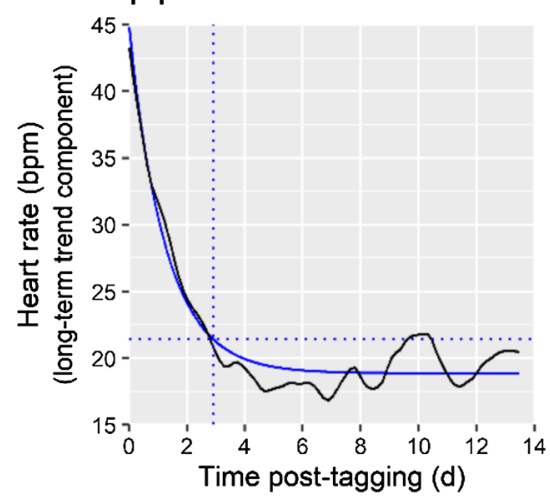

F7

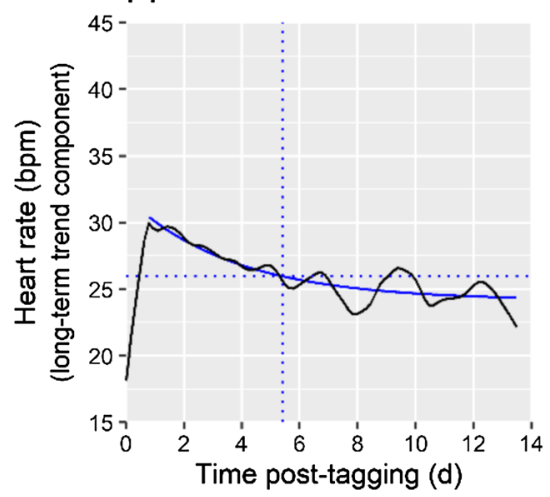

F2

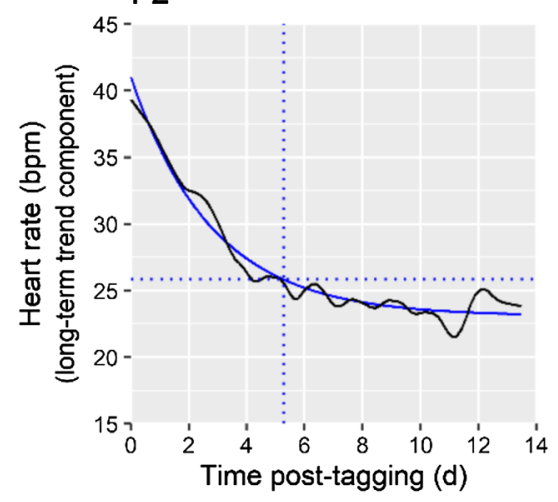

F5

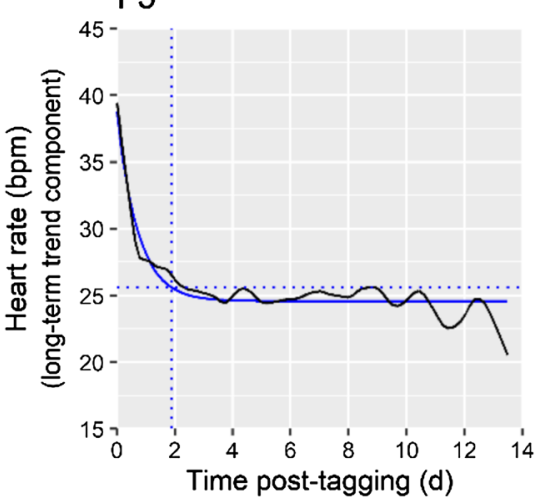

F8

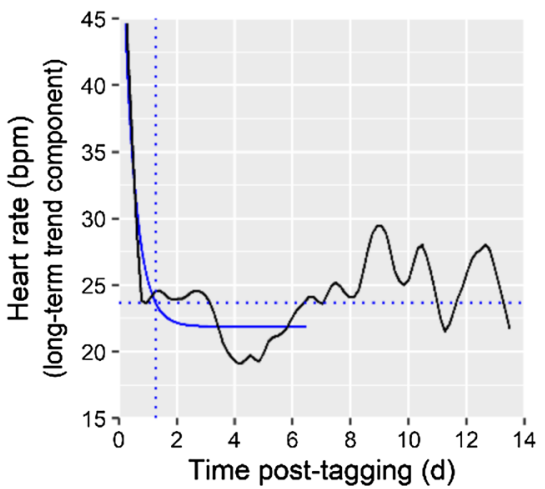

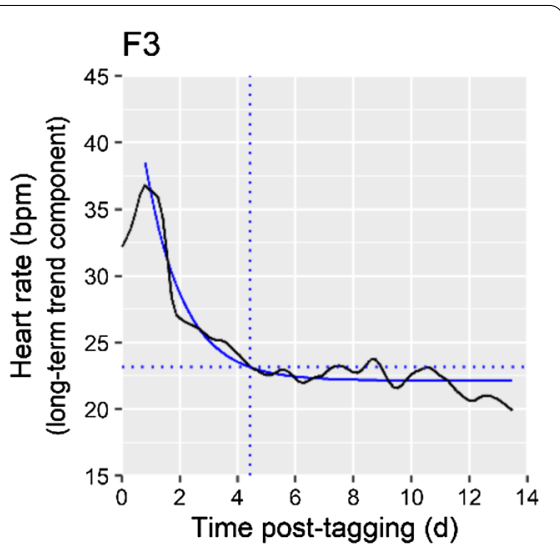

F6

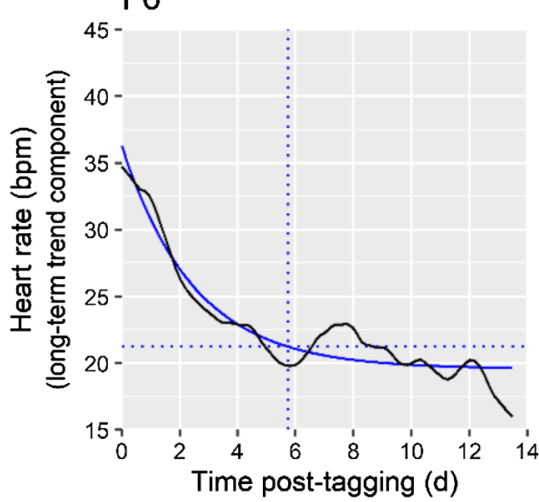

F9

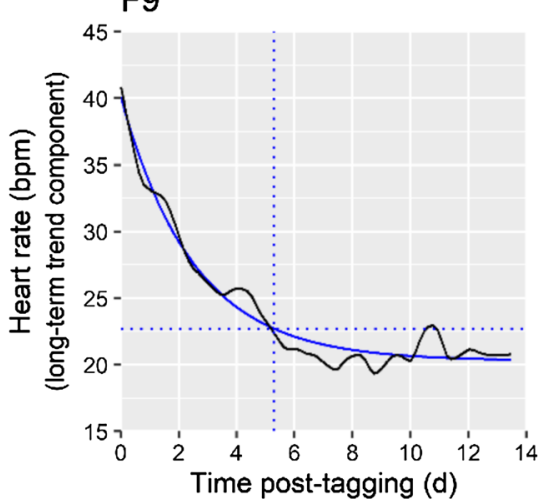

Fig. 3 Long term trend in heart rate. Each panel represents data from one individual fish. The continuous black line shows the long-term trend component; the continuous blue line shows the fitted exponential decay model. The dashed horizontal line shows the threshold used to define a structural change; the dashed vertical line shows the breakpoint indicating when the structural change occurs between classified pre- and post-recovery phases 
showed considerable temporal variation, depending on the tagged individual. For example, the trend component for fish F4 showed a sharp decline during the first day after tagging, but this then fluctuated for the remainder of the 2-week post-tagging period. The activity trend component also showed a pattern consistent with an exponential decay (Fig. 4), except for one fish (fish F8) where an exponential decay model could not be fitted due to the activity trend component peaking $\approx 7$ days after tagging. Two fish (fish F1 and F2) showed an exponential decline in activity but did not reach a

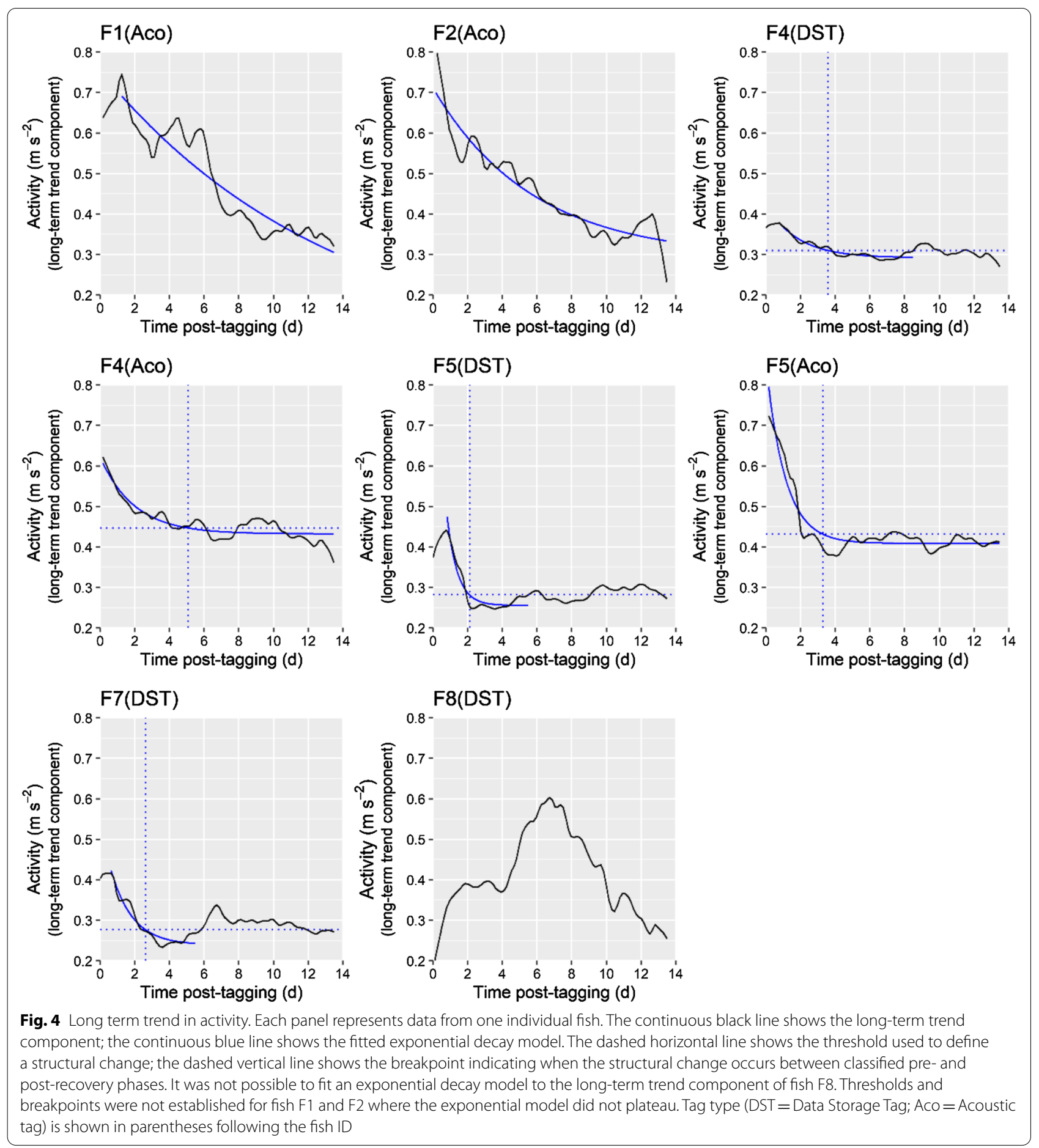


plateau during the study period, suggesting that these fish has not fully recovered in terms of activity.

Time to recovery (as defined by the location of the breakpoint between pre- and post-recovery phases) varied between individuals, and the metric used (heart rate or activity, Figs. 3, 4, Table 2). The mean threshold value for heart rate in a 'recovered' individual was $23.8 \mathrm{bpm}$ (range $=21.2-26.0, \mathrm{SD}=1.18, n=9$ ). The mean time to reach this threshold (i.e. breakpoint between pre-recovery and post-recovery) was 4.1 days (range $=1.3-5.8$, $\mathrm{SD}=1.7, n=9$ ). The threshold for activity recovery was greater for the acoustic tags (mean $=0.44 \mathrm{~m} \mathrm{~s}^{-2}, n=2$ ) than the DSTs (mean $=0.29 \mathrm{~m} \mathrm{~s}^{-2}, n=3$ ), reflecting the higher activity values registered by the acoustic tags. For the activity tags where there was evidence of recovery, the mean time taken to reach the threshold was similar to that for the heart rate tags (mean 3.3 days, range $=2.1-$ $5.7, \mathrm{SD}=0.09$ ). For the two individuals that were each tagged with two activity tags, the identified breakpoints between the parts of the time series classified as pre- and post-recovery depended on the tag: in both individuals, the threshold to reach post-recovery occurred later for the acoustic tag than the DST.

Although raw values of mean heart rate on the day of anaesthesia and surgery (mean $=36.0 \mathrm{bpm}$, range $=24.6-$ 45.6, $\mathrm{SD}=5.6, n=9)$ varied more than the recovery threshold (mean $=23.8 \mathrm{bpm}$, range $=21.2-26.0$, $\mathrm{SD}=1.8, n=9$, Table 2), there was a clear declining trend for all tagged individuals. With the exception of one

Table 2 Recovery based on heart rate and activity sensors

\begin{tabular}{|c|c|c|c|c|}
\hline \multirow[t]{2}{*}{ Tag ID } & \multicolumn{2}{|c|}{ Heart rate recovery } & \multicolumn{2}{|c|}{ Activity recovery } \\
\hline & $\begin{array}{l}\text { Threshold } \\
\text { (bpm) }\end{array}$ & Time (days) & $\begin{array}{l}\text { Threshold } \\
\left(\mathrm{m} \mathrm{s}^{-2}\right)\end{array}$ & Time (days) \\
\hline F1 & 24.90 & 4.33 & No rec & No rec \\
\hline F2 & 25.83 & 5.27 & No rec & No rec \\
\hline F3 & 23.17 & 4.42 & & \\
\hline \multirow[t]{2}{*}{$\mathrm{F} 4$} & 21.43 & 2.92 & 0.31 & 3.59 \\
\hline & & & $0.45^{*}$ & $5.08^{*}$ \\
\hline \multirow[t]{2}{*}{ F5 } & 25.63 & 1.89 & 0.28 & 2.10 \\
\hline & & & $0.43^{*}$ & $3.30^{*}$ \\
\hline F6 & 21.24 & 5.75 & & \\
\hline F7 & 25.97 & 5.41 & 0.28 & 2.60 \\
\hline F8 & 23.68 & 1.27 & No fit & No fit \\
\hline F9 & 22.71 & 5.29 & & \\
\hline Mean & 23.84 & 4.06 & 0.35 & 3.3 \\
\hline
\end{tabular}

Activity sensors with a * suffix indicate acoustic tags. "No fit" indicates that the long-term component of the time-series did not follow an exponential decline and that an exponential model could not be fitted; "No rec" indicates that it was possible to fit an exponential model to the time-series but that recovery thresholds and times were not assigned because the fitted exponential model did plateau individual (F8, Fig. 4), there was a similar trend for activity: day of anaesthesia and surgery, mean $=0.64 \mathrm{~m} \mathrm{~s}^{-2}$, range $=0.39-0.92, \mathrm{SD}=0.20, n=7$; recovery threshold, mean $=0.36 \mathrm{~m} \mathrm{~s}^{-2}$, range $=0.28-0.43 \mathrm{SD}=0.07, n=7$. For both heart rate and activity, raw values pre-recovery were significantly greater than those post-recovery (onesided Wilcoxon's signed-rank test: heart rate, $V=45$, $p=0.002, n=9$; activity, $V=28, p=0.008, n=7$ ).

\section{Discussion}

The current study showed plateauing of most time-series, indicative of recovery, within the 14 days of the experiment. Two activity tags, F1(Aco) and F2(Aco), however, did not show plateauing, suggesting that the tagged fish had not fully recovered in terms of activity during this period. Other time-series showed gentle gradients even after the recovery breakpoint (for example, the F6 heart rate tag) so the definition of the point of recovery of some individuals as having fully recovered is less robust. However, identified breakpoints generally corresponded with systematic changes in the time-series. For example, the breakpoint on the F6 heart rate tag occurred in a trough separating the sharp initial decline over the first 5.75 days with the gentle gradient afterwards, so it is reasonable to infer that the identified breakpoint corresponded to the transition to post-recovery. The modelling approach used here allowed for a consistent method for establishing the time until recovery among a group of time-series. It should be noted, however, that estimated times until recovery is dependent on modelling approach used. For instance, fitting an exponential model to raw-rather than detrended timeseries, or using a different method to establish a breakpoint between pre- and post-recovery parts of the time-series, would yield different estimates. The exponential model used in this study is a well-validated method for modelling physiological recovery [39] but alternative approaches may also be considered (e.g. [27]). The sample size of fish in this study was small $(N=9)$; a larger sample size would allow a better quantification of the range of behaviour during recovery and allow better selection of the modelling approach.

The heart rate data suggest that the tagged Atlantic salmon in our study could only be considered fully recovered from the anaesthesia and surgical procedure of intraperitoneal tag implantation after an average of $\approx 4$ and up to a maximum of 6 days post-surgery. While some studies have indicated longer recovery times post-tagging [32], our observations concur with several previous studies that have reported similar lengths of recovery posttagging as our study [11, 16, 24, 25, 28]. Although some data series from the tagged fish in our study may visually appear to continue declining after fulfilling the recovery threshold criteria, these changes were not found to be 
statistically significant. Recovery results based on activity data varied more in the recovery threshold criteria and time to recovery than heart rate, suggesting it might be a less consistent indicator of recovery between individuals. Moreover, both the temporal patterns and absolute values changed less for activity than heart rate between post-tagging and post-recovery periods, implying a lower ratio between the baseline pattern (i.e. circadian variations) and the changes in activity caused by the tagging procedure. Together, these factors suggest that activity may be a less consistent indicator of post-tagging recovery than heart rate, and that heart rate might be a generally more sensitive indicator than activity, especially for post-tagging recovery.

It is also important to note that there were individual variations in the recovery time assessed from heart rate. Although inter-individual variation in recovery time might be an inherent effect one should expect when tagging A. salmon, we did find that mature fish had a lower heart-rate recovery time than immature fish. However, the low sample size did not provide enough statistical power to robustly test influences on recovery time, so we recommend further studies with larger sample sizes to increase power in analyses of potential influences.

Based on these results, we urge caution on using telemetry data collected after anaesthesia and surgery without first ensuring that the fish are fully recovered $[1,23]$. Biosensors that measure heart rate and/or activity can be potent tools in such evaluations, as they provide quantitative, high-resolution data that will be both more consistent, precise and objective in capturing the full post-anaesthesia/surgery effects than e.g. comparing behavioural observations of tagged vs. untagged fish.

Alternative parameters that could be used to assess post-tagging recovery in individual fish include blood glucose, lactate or pulse oximetry/ppg. These could provide a more direct assessment of stress levels in salmon, but we are not aware of any commercial electronic tags able to sense such parameters in live fish. Other techniques based on measuring cortisol in faecal matter [40] or bioelectric field monitoring akin to that used by sharks [41] could potentially result in future solutions that could be used evaluate recovery in a less invasive and independent manner, where the fish are monitored before, during and after the procedure. However, these methods are still to be developed to a stage where they can be applied to free-swimming fish, at least in large groups under commercial production conditions, and would only be able to provide information on a group level.

All three DST types tested in this experiment appeared to be suitable for applications on Atlantic salmon as all tagged fish provided valid heart rate data. Moreover, the activity proxy computed from the DSTs containing accelerometers were found to be comparable to those measured by the acoustic tags (see [27] for details on this comparison). The lower absolute amplitude of the activity proxies computed from the DST data was probably caused by them sampling at a lower frequency $(1 \mathrm{~Hz})$ than the acoustic tags $(5 \mathrm{~Hz})$, thereby capturing fewer high-frequency components. The surgical procedure used to implant the heart rate tags was much simpler than the procedure needed for multivariate implants recently used in rainbow trout by Brijs et al. [31] but was more comprehensive and invasive than that used for conventional intraperitoneal tag placement. It is likely that less complex surgical procedures would lead to shorter recovery times in Atlantic salmon, as previously found for rainbow trout $[42,43]$. However, it is probably reasonable to be conservative with respect to recovery times, especially if the data are to be used e.g. as a management tool in aquaculture applications or to evaluate stress effects on fish in conjunction with ecological studies. Using data from fish that are still recovering from post-anaesthesia/ surgery effects in such applications could result in suboptimal management decisions or erroneous conclusions that could have ramifications beyond the study itself.

The fish included in the analyses exhibited heart rates that gradually stabilised at daily means between 21 and $26 \mathrm{bpm}$ (daily variations between 15 and $30 \mathrm{bpm}$, similar to that observed by for adult A. salmon of mean fork length of $62.3 \mathrm{~cm}$ at $4{ }^{\circ} \mathrm{C}$ by Lucas [36]). Due to the similarities across tanks and individuals, this range in heart rate may be typical for Atlantic salmon of this size and with the prevailing temperatures. Moreover, all individuals in tanks 1, 2 and 4 had similar circadian rhythms (higher heart rates during daytime than at night) and gradual post-surgery declines in mean daily heart rate (from more than $30 \mathrm{bpm}$ after surgery to $21-26 \mathrm{bpm}$ after up to 6 days). This implies a regularity across individuals that increases the likelihood that heart rate may function as a consistent stress indicator in Atlantic salmon that may be used to assess fish recovery after tagging. The tagged fish in tank 3 were excluded from the study due to inter-individual aggression. These individuals demonstrated measured heart rates that differed from the others both in individual and aggregate values. Although these fish also showed signs of circadian variation in heart rate, the mean value did not appear to decline over the days following tagging, an effect that was attributed to inter-individual aggression, all else being held equal. This may indicate that the stress induced by the aggression between the two males in this tank overrode the stress response due to recovery. A potential interpretation of this is that the aggressive encounters caused chronically elevated stress levels that masked the recovery stress caused by handling, anaesthesia and surgery. This could 
further mean that recovery stress can be difficult to monitor if the fish are simultaneously influenced by independent external events, such as individual interactions due to dominance hierarchies $[44,45]$.

Based on established knowledge on how salmon swimming speeds are affected by variations in light intensity [46], as well as previous telemetry studies applying similar activity proxies on salmon in sea-cages (e.g. [10]), we expected to see a circadian rhythm in activity where activity was higher during the day than at night in the present study. In contrast to these expectations, the circadian trends in the activity of our fish were on average higher during night-time than during the day. A similar "inverse circadian" rhythm was observed in salmon reared in fish tanks during the period after tagging by Kolarevic et al. [30] and could imply that a "normal circadian" activity rhythm may arise only after the salmon have recovered after tagging in tanks. Conversely, the circadian rhythm in heart rate was more like expected (higher during daytime), meaning that the fish displayed generally higher heart rates when measured activity was low than when activity was high. This may seem counterintuitive as one would expect more active fish to display higher heart rates since salmon tend to display increased heart rates with increased swimming activity [47]. However, it is possible that the higher heart rates during daytime were caused by effects such as feeding activity [48, 49] or perceived increased predation risk due to higher light levels [50]. These results are unexpected and very interesting, but further extrapolations and discussions on this matter would probably require further experiments with more data.

Although this study underlines the importance of critical evaluation with regards to recovery from anaesthesia and surgery when using telemetry, the data collected also highlight the importance of telemetry as a method for studying free-swimming fish. The heart rate and activity values for all tagged fish eventually plateaued, possibly indicating that they all recovered from the anaesthesia/surgery, and posthumous pathology revealed no inflammations or other apparent morphological signs of reduced welfare due to the surgical procedures. Even though the low water temperatures during the experiment may have led to handling and surgery having less impact on the fish, the tagging procedure used here was more complex than conventional intraperitoneal tagging. It is thus reasonable to conclude that fish carrying telemetry tags can be considered representative members of the group they were selected from once they are fully recovered from anaesthesia and surgery, provided that they were a representative selection to begin with. However, this also requires that the recommendations on ratio between tag size and fish size are not exceeded (e.g. "the
$2 \%$ rule", [2]). Since we worked with adult salmon with a mean weight of $2100 \mathrm{~g}$, and the maximum tag weight carried by the fish was $22.6 \mathrm{~g}$ (around 1\% of the fish body mass) this was not a challenge in our study.

\section{Future research and potential technological improvements} Since this study only focused on Atlantic salmon exposed to one set of environmental conditions, it is difficult to assess if these concerns are also relevant for other species, and/or fish under different conditions. Similar studies on rainbow trout using the same tag type found that they recovered 72-96 $\mathrm{h}$ after surgery [28], which was shorter than the Atlantic salmon in the present study. Moreover, wounds in Atlantic salmon are known to heal faster in warmer temperatures than in cold water [51], suggesting that the low water temperatures in the present study may have contributed to longer recovery periods. These elements suggest that species-specific effects or differences in external environmental conditions are important to consider when studying recovery times. Future studies on the relationship between heart rate and post anaesthesia/surgery recovery time should therefore be conducted for other species of interest, across relevant temperature ranges, to obtain a more complete picture of this relationship.

In the present experiment, the fish were kept in groups in small tanks. To investigate how recovery time is affected by eventual scaling effects and social/inter-individual effects arising due to group dynamics, future studies addressing post-tagging effects should be done with a larger number of tagged fish at larger spatial scales. This would also enable a deeper scrutiny into individual variations in recovery, as a higher number of tagged fish would provide a good foundation for finding statistical relationships on the individual level. Although our present results imply that inter-individual variations are a prominent feature in the recovery time of tagged salmon, a larger sample number will be necessary to properly conclude upon the nature of such variations. To increase the relevance of a larger follow-up study, it could be done in fish cages in the marine environment, perhaps first by using meso-scale size cages containing fewer fish than a commercial cage but at similar densities, and then moving to full-scale studies to cover all steps in the transition from lab to industrial scale.

\section{Conclusion}

The main conclusion from this study is that the Atlantic salmon in these experiments required an average of $\approx 4$ and up to a maximum interval of 6 days of recovery after anaesthesia and surgery before their heart rates returned to assumed baseline routine values. Moreover, although observation of behaviour and/or activity may 
alone be insufficient to assess that the fish has physiologically recovered, activity measurements indicated similar recovery periods to those based on heart rate, although there was a longer maximum period of 10 days. We, therefore, urge caution when using data collected after surgery and anaesthesia in studies using biologging/ telemetry tags. Assuming that we want all individuals to be recovered, our study thus implies that only data collected after 6 days recovery time should be used for further analyses. However, this recommendation would only be applicable to studies featuring Atlantic salmon reared in similar experimental conditions as we used. Since recovery time will vary with factors such as fish species, water temperature, invasiveness of the surgery, anaesthesia time, fish density and physical scale, it is difficult to make general recommendations on when one can assume the fish to be recovered from tagging, and the data to be safe for use in biological analyses. However, by conducting experiments similar to the present study where these parameters are varied, a more complete picture of how we need to account for fish recovery after tagging in telemetry studies may be obtained.

\section{Supplementary Information}

The online version contains supplementary material available at https://doi. org/10.1186/s40317-020-00226-8.

Additional file 1: Figure S1. Measured heart rate for Tag IDs F1-F4. The $\mathrm{y}$-axis upper limit has been constrained to $50 \mathrm{bpm}$. Figure S2. Measured heart rate for Tag IDs F5-F9. The y-axis upper limit has been constrained to 50 bpm. Figure S3. Measured activity for acoustic tags. Figure S4. Measured activity for DSTs. The $y$-axis upper limit has been constrained to $5 \mathrm{~m} \mathrm{~s}^{-2}$. Figure S5. Circadian component of heart rate. Each panel represents data from one individual fish. Figure S6. Circadian component of the activity. Each panel represents data from one individual fish.

\section{Acknowledgements}

In addition to thanking the Research Council of Norway for financial support (see "Funding"), we would like to thank the crew at NINA's research station at Ims, particularly Knut Bergesen, for their effort in the experiments. We would also like to thank Asgeir Bjarnason at Star Oddi LTD and Erik Høy at Thelma Biotel AS for collaboration in specifying the loggers and transmitter tags used in the study. Bengt Finstad acknowledges the financial support obtained from DNV GL, while Martin Føre acknowledges the financial support from Salmar ASA/Salmar Ocean.

\section{Authors' contributions}

MF manages the funding project, participated in the planning and execution of the experiments, and did the main job in preparing the manuscript. ES participated in the experiments, prepared the data, and was central in analysing the data. $F \varnothing$ was central in planning the experiments and conducted the surgery to equip the fish with the tags (together with AG). AG programmed the heart rate loggers, conducted the surgery to equip the fish with the tags (together with $F \varnothing$ ) and contributed in the data analyses. JAA participated in the planning of the experiments and data analyses. BF was the main person behind the planning and execution of the experiment and participated in the experiment and data analyses. $\mathrm{RH}$ was responsible for the statistical analyses and contributed to the general processing of data. IU had a key role in planning the experiments and had the original idea behind the study resulting in this article. All authors have contributed to writing the manuscript. All authors read and approved the final manuscript.

\section{Funding}

This study was funded by the Research Council of Norway (NFR Project Number 280864)

\section{Availability of data and materials}

The datasets used and/or analysed during the current study are available from the corresponding author on reasonable request.

\section{Ethics approval and consent to participate}

All fish handling and surgery were made in compliance with the Norwegian animal welfare act and were approved by the Norwegian Animal Research Authority (Permit No. 18/18431).

\section{Consent for publication}

Not applicable.

\section{Competing interests}

The authors declare that they have no competing interests.

\section{Author details}

${ }^{1}$ Department of Engineering Cybernetics, Norwegian University of Science and Technology, 7491 Trondheim, Norway. ${ }^{2}$ SINTEF Ocean, 7465 Trondheim, Norway. ${ }^{3}$ Norwegian Institute for Nature Research, 7485 Trondheim, Norway. ${ }^{4}$ Department of Animal Environment and Health, Swedish University of Agricultural Sciences, 53231 Skara, Sweden. ${ }^{5}$ Department of Biology, Norwegian University of Science and Technology, 7491 Trondheim, Norway.

Received: 16 April 2020 Accepted: 9 December 2020

Published online: 05 January 2021

\section{References}

1. Cooke SJ, Woodley CM, Eppard MB, Brown RS, Nielsen JL. Advancing the surgical implantation of electronic tags in fish: a gap analysis and research agenda based on a review of trends in intracoelomic tagging effects studies. Rev Fish Biol Fish. 2011;21(1):127-51.

2. Thorstad EB, Rikardsen AH, Alp A, Økland F. The use of electronic tags in fish research-an overview of fish telemetry methods. Turk J Fish Aquat Sci. 2013;13(5):881-96.

3. Føre M, Alfredsen JA, Gronningsater A. Development of two telemetrybased systems for monitoring the feeding behaviour of Atlantic salmon (Salmo salar L.) in aquaculture sea-cages. Comput Electron Agric. 2011;76(2):240-51.

4. Taylor MD, Babcock RC, Simpfendorfer CA, Crook DA. Where technology meets ecology: acoustic telemetry in contemporary Australian aquatic research and management. Mar Freshw Res. 2017;68(8):1397-402.

5. Welsh JQ, Bellwood DR. Spatial ecology of the steephead parrotfish (Chlorurus microrhinos): an evaluation using acoustic telemetry. Coral Reefs. 2012;31(1):55-65.

6. Cooke SJ, Bunt CM, Schreer JF. Understanding fish behavior, distribution, and survival in thermal effluents using fixed telemetry arrays: a case study of smallmouth bass in a discharge canal during winter. Environ Manag. 2004;33(1):140-50.

7. Crossin GT, Heupel MR, Holbrook CM, Hussey NE, Lowerre-Barbieri SK, Nguyen VM, Raby GD, Cooke SJ. Acoustic telemetry and fisheries management. Ecol Appl. 2017;27(4):1031-49.

8. Hussey NE, Kessel ST, Aarestrup K, Cooke SJ, Cowley PD, Fisk AT, Harcourt RG, Holland KN, Iverson SJ, Kocik JF, Flemming JEM. Aquatic animal telemetry: a panoramic window into the underwater world. Science. 2015;348(6240):1255642.

9. Føre M, Frank K, Norton T, Svendsen E, Alfredsen JA, Dempster T, Eguiraun H, Watson W, Stahl A, Sunde LM, Schellewald C, Skøien KR, Alver MO, Berckmans D. Precision fish farming: a new framework to improve production in aquaculture. Biosyst Eng. 2018;173:176-93.

10. Føre M, Svendsen E, Alfredsen JA, Uglem I, Bloecher N, Sveier H, Sunde LM, Frank K. Using acoustic telemetry to monitor the effects of crowding and delousing procedures on farmed Atlantic salmon (Salmo salar). Aquaculture. 2018;495:757-65.

11. Brijs J, Sandblom E, Axelsson M, Sundell K, Sundh H, Huyben D, Broström R, Kiessling A, Berg C, Gräns A. The final countdown: continuous 
physiological welfare evaluation of farmed fish during common aquaculture practices before and during harvest. Aquaculture. 2018;495:903-11.

12. Johansson D, Ruohonen K, Juell JE, Oppedal F. Swimming depth and thermal history of individual Atlantic salmon (Salmo salar L.) in production cages under different ambient temperature conditions. Aquaculture. 2009;290(3-4):296-303.

13. Wright DW, Stien LH, Dempster T, Oppedal F. Differential effects of internal tagging depending on depth treatment in Atlantic salmon: a cautionary tale for aquatic animal tag use. Curr Zool. 2018;65:665-73.

14. Campbell HA, Bishop CM, Davies DA, Egginton S. Recording long-term heart rate in Paranotothenia angustata using an electronic datalogger. J Fish Biol. 2005;67(4):1150-6.

15. Connors KB, Scruton D, Brown JA, McKinley RS. The effects of surgically implanted dummy radio transmitters on the behaviour of wild Atlantic salmon smolts. In: Aquatic telemetry. Dordrecht: Springer; 2002. p. 231-7.

16. Jepsen N, Davis LE, Schreck CB, Siddens B. The physiological response of Chinook salmon smolts to two methods of radio-tagging. Trans Am Fish Soc. 2001:130(3):495-500.

17. Thoreau X, Baras E. Evaluation of surgery procedures for implanting telemetry transmitters into the body cavity of tilapia Oreochromis aureus. Aquat Living Resour. 1997;10(4):207-11.

18. Ellis T, North B, Scott AP, Bromage NR, Porter M, Gadd D. The relationship between stocking density and welfare in farmed rainbow trout. J Fish Biol. 2002;61:493-531.

19. Pickering AD. Stress responses of farmed fish. Biology of Farmed Fish. Sheffield: Sheffield Academic Press; 1998. p. 222-55.

20. Schreck CB. Accumulation and long-term effects of stress in fish. In: Moberg GP, Mench JA, editors. The biology of animal stress. Wallingford: CAB International; 2000. p. 147-58

21. Wedemeyer GA. Effect of rearing conditions on the health and physiological quality of fish in intensive fish culture. In: Iwama GK, Pickering $A D$, Sumpter JP, Schreck CB, editors. Fish stress and health in aquaculture, vol. 62. Society for Experimental Biology Seminar Series. Cambridge: Cambridge University Press; 1997. p. 35-72.

22. Iwama GK, Afonso LOB, Vijayan MM, Iwama GK, Afonso LOB, Vijayan MM. Stress in fishes. In: Ewans DE, Claiborne JB, editors. The physiology of fishes. Boca Raton: CRC Press; 2006. p. 319-42.

23. Mulcahy DM. Surgical implantation of transmitters into fish. ILAR J. 2003;44(4):295-306.

24. Bridger CJ, Booth RK. The effects of biotelemetry transmitter presence and attachment procedures on fish physiology and behavior. Rev Fish Sci. 2003;11(1):13-34.

25. Martinelli TL, Hansel HC, Shively RS. Growth and physiological responses to surgical and gastric radio transmitter implantation techniques in subyearling chinook salmon (Oncorhynchus tshawytscha). In: Advances in invertebrates and fish telemetry. Dordrecht: Springer; 1998. p. 79-87.

26. Barton BA, Schreck CB. Metabolic cost of acute physical stress in juvenile steelhead. Trans Am Fish Soc. 1987;116(2):257-63.

27. Svendsen E, Føre M, Økland F, Gräns A, Hedger RD, Alfredsen JA, Uglem I, Rosten CM, Frank K, Erikson U, Finstad B. Heart rate and swimming activity as stress indicators for Atlantic salmon (Salmo salar). Aquaculture. 2020;531:735804.

28. Brijs J, Sandblom E, Rosengren M, Sundell K, Berg C, Axelsson M, Gräns A. Prospects and pit-falls of using heart rate to the welfare of rainbow trout (Oncorhynchus mykiss) in aquaculture. Aquaculture. 2019;509:188-97.

29. Hjelmstedt P, Sundh H, Brijs J, Ekström A, Sundell KS, Berg C, Sandblom E, Bowman J, Morgenroth D, Gräns A. Effects of prophylactic antibiotictreatment on post-surgical recovery following intraperitoneal bio-logger implantation in rainbow trout. Sci Rep. 2020;10(1):1-9.

30. Kolarevic J, Aas-Hansen $\varnothing$, Espmark $\AA$, Baeverford G, Terjesen BF, Damsgård $B$. The use of acoustic acceleration transmitter tags for monitoring of Atlantic salmon swimming activity in recirculating aquaculture systems (RAS). Aquacult Eng. 2016;72-73:30-9.

31. Brijs J, Sandblom E, Axelsson M, Sundell K, Sundh H, Kiessling A, Berg C, Gräns A. Remote physiological monitoring provides unique insights on the cardiovascular performance and stress responses of freely swimming rainbow trout in aquaculture. Sci Rep. 2019;9(1):9090.

32. Hvas M, Folkedal O, Oppedal F. Heart rate bio-loggers as welfare indicators in Atlantic salmon (Salmo salar) aquaculture. Aquaculture. 2020:529:735630.

33. Coyle SD, Durborow RM, Tidwell JH. Anesthetics in aquaculture, vol. 3900. Texas: Southern Regional Aquaculture Center; 2004.

34. Leys C, Ley C, Klein O, Bernard P, Licata L. Detecting outliers: do not use standard deviation around the mean, use absolute deviation around the median. J Exp Soc Psychol. 2013;49(4):764-6.

35. Miller J. Reaction time analysis with outlier exclusion: bias varies with sample size. Q J Exp Psychol. 1991;43(4):907-12.

36. Lucas MC. Heart rate as an indicator of metabolic rate and activity in adult Atlantic salmon, Salmo salar. J Fish Biol. 1994;44(5):889-903.

37. Becker R, Chambers JM, Wilks AR. 2018. The new S language. CRC Press.

38. Cleveland RB, Cleveland WS, MCRae JE, Terpenning I. STL: a seasonal-trend decomposition procedure based on loess. J Off Stat. 1990;6:3-73.

39. Bartels-Ferreira R, de Sousa ED, Trevizani GA, Silva LP, Nakamura FY, Forjaz CLM, Lima JRP, Pecanha T. Can a first-order exponential decay model fit heart rate recovery after resistance exercise? Clin Physiol Funct Imaging. 2015;35(2):98-103.

40. Cao Y, Tveten AK, Stene A. Establishment of a non-invasive method for stress evaluation in farmed salmon based on direct fecal corticoid metabolites measurement. Fish Shellfish Immunol. 2017;66:317-24.

41. Kalmijn AJ. Bioelectric fields in sea water and the function of the ampullae of Lorenzini in elasmobranch fishes (No. SIO-REF-72-83). La Jolla: Scripps Institution of Oceanography; 1972.

42. Altimiras J, Larsen E. Non-invasive recording of heart rate and ventilation rate in rainbow trout during rest and swimming. Fish go wireless! J Fish Biol. 2000;57(1):197-209.

43. Gräns A, Sandblom E, Kiessling A, Axelsson M. Post-surgical analgesia in rainbow trout: is reduced cardioventilatory activity a sign of improved animal welfare or the adverse effects of an opioid drug? PLOS ONE. 2014;9(4):e95283.

44. Cubitt KF, Winberg S, Huntingford FA, Kadri S, Crampton VO, Øverli $\varnothing$. Social hierarchies, growth and brain serotonin metabolism in Atlantic salmon (Salmo salar) kept under commercial rearing conditions. Physiol Behav. 2008:94(4):529-35.

45. Sloman KA, Metcalfe NB, Taylor AC, Gilmour KM. Plasma cortisol concentrations before and after social stress in rainbow trout and brown trout. Physiol Biochem Zool. 2001;74(3):383-9.

46. Oppedal F, Dempster T, Stien LH. Environmental drivers of Atlantic salmon behaviour in sea-cages: a review. Aquaculture 2011;311(1-4):1-18

47. Hvas M, Folkedal O, Oppedal F. Heart rates of Atlantic salmon Salmo salar during a critical swim speed test and subsequent recovery. J Fish Biol. 2020. https://doi.org/10.1111/jfb.14561.

48. Eliason EJ, Higgs DA, Farrell AP. Postprandial gastrointestinal blood flow, oxygen consumption and heart rate in rainbow trout (Oncorhynchus mykiss). Comp Biochem Physiol A Mol Integr Physiol. 2008;149(4):380-8.

49. Gräns A, Albertsson F, Axelsson M, Olsson C. Postprandial changes in enteric electrical activity and gut blood flow in rainbow trout (Oncorhynchus mykiss) acclimated to different temperatures. J Exp Biol. 2009:212(16):2550-7.

50. Johnsson JI, Höjesjö J, Fleming IA. Behavioural and heart rate responses to predation risk in wild and domesticated Atlantic salmon. Can J Fish Aquat Sci. 2001;58(4):788-94.

51. Jensen LB, Wahli T, McGurk C, Eriksen TB, Obach A, Waagbø R, Handler A, Tafalla C. Effect of temperature and diet on wound healing in Atlantic salmon (Salmo salar L.). Fish Physiol Biochem. 2015;41(6):1527-43.

\section{Publisher's Note}

Springer Nature remains neutral with regard to jurisdictional claims in published maps and institutional affiliations. 